Studi Francesi

STUDI

Rivista quadrimestrale fondata da Franco Simone

166 ( | LVI) | 2012

Varia

\title{
Aa. Vv., «Cahiers Mérimée», 3
}

\section{Michel Arrous}

\section{OpenEdition}

\section{Journals}

\section{Édition électronique}

URL : https://journals.openedition.org/studifrancesi/4740

DOI : $10.4000 /$ studifrancesi.4740

ISSN : 2421-5856

\section{Éditeur}

Rosenberg \& Sellier

\section{Édition imprimée}

Date de publication : 1 avril 2012

Pagination : 167-168

ISSN : 0039-2944

\section{Référence électronique}

Michel Arrous, «Aa. VV., «Cahiers Mérimée», 3 », Studi Francesi [En ligne], 166 (I | LVI) | 2012, mis en ligne le 30 novembre 2015, consulté le 19 novembre 2021. URL : http://journals.openedition.org/ studifrancesi/4740 ; DOI : https://doi.org/10.4000/studifrancesi.4740

Ce document a été généré automatiquement le 19 novembre 2021.

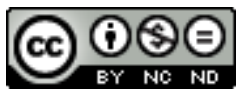

Studi Francesi è distribuita con Licenza Creative Commons Attribuzione - Non commerciale - Non opere derivate 4.0 Internazionale. 


\title{
Aa. Vv., «Cahiers Mérimée», 3
}

\author{
Michel Arrous
}

\section{RÉFÉRENCE}

«Cahiers Mérimée», Paris, Éditions Classiques Garnier, 2011, 3, pp. 164.

1 Une lecture attentive de la Correspondance générale et une bonne connaissance de la politique européenne permettent à Alain schmiтt de donner de l'action politique de Mérimée, qui ne fut pas un bonapartiste sans réserve, tout en étant fidèle à la dynastie, une vision renouvelée. Dans Mérimée, observateur critique et soutien actif de Napoléon III (pp.11-33), A. sснмітт rappelle que le jugement de l'écrivain sur l'empereur, d'abord globalement positif, se fit de plus en plus critique à partir de 1859, qu'il s'agisse de politique étrangère ou de politique intérieure. Les pages les plus nouvelles sont consacrées à «Mérimée, agent de la politique impériale», autrement dit à un Mérimée assurant auprès du gouvernement de Londres et de ses correspondants en Angleterre, Edward Ellice ou Antonio Panizzi, une véritable action de lobbying en faveur de la France. Cela est particulièrement net lors de la crise franco-britannique de 1860. Un autre pan méconnu de son activité officielle est abordé par Marie GALVEZ, Mérimée, les bibliothèques et la bibliothéconomie (pp.35-51): le rôle de Mérimée à la tête d'une commission chargée de réorganiser la «noire caverne» de la Bibliothèque impériale en 1858 est retracé dans le détail, mais on regrettera que le rapport qu'il rédigea n'ait pas été suffisamment exploité.

2 Suivent trois études consacrées à Lokis, au Théâtre de Clara Gazul et aux échos byroniens dans l'œuvre de Mérimée. Pour Paule PETITIER, dans “Lokis": le trompe-l'œil archéologique (pp.53-63), l'ironie mériméenne tourne en dérision les principes rationalistes et bat en brèche l'explication généalogique de l'étrange conduite du comte. On a affaire à un fantastique critique. Caroline JULLIOT, avec "L'inquisiteur nouveau est arrivé?" Mérimée à la croisée des sensibilités et des influences (pp.66-80), montre qu'à la différence de Hugo, Schiller, et plus tard Dostoïevski, l'inquisiteur chez le voltairien Mérimée relève du stéréotype de l'Espagne qu'il récuse, ce qui ne l'empêche pas de voir en lui un «avatar 
de la loi de la sauvagerie». Il s'agit d'un personnage auquel il ne s'est jamais sérieusement intéressé, à l'exception sans doute de Philippe II, incarnation du principe de destruction et maniaque de la loi, même quand il la transgresse. Dans Mérimée, Byron et le cant français. Résonances byroniennes dans les nouvelles parisiennes (pp. 81-98), partant de la constante admiration de Mérimée pour le Don Juan de Byron, Peter coGmAN relève les caractéristiques de la société et certains comportements individuels dans Le Vase étrusque, La Double Méprise et particulièrement Arsène Guillot, récits où les formes d'hypocrisie et de mauvaise foi propres à la société française de la Restauration, reprennent, non sans quelques différences, les analyses et les critiques de Byron.

Hélène LAPLACE-CLAVERIE traite un aspect peu connu des avatars de la célébrissime nouvelle de Mérimée: "Carmen" et les chorégraphes du xxe siècle (pp. 99-107). D'une dizaine d'adaptations émergent celles d'Antonio Gades (1983), Karine Saporta (1991) et Mats Ek (1992); mais la plus célèbre demeure celle de Roland Petit (1949) qui non seulement se démarqua de la version lyrique mais sut aussi ajouter une touche de parodie.

4 De l'œuvre «colossale» de Juliette Adam, Philippe GARNIER a retenu les Souvenirs (1902-1910) et leur fortune chez les mériméistes. On trouvera dans Mérimée à travers les "Souvenirs" de Juliette Adam (pp. 109-129) l'histoire de cette amitié fidèle qui débuta en 1861-1862, ponctuée de témoignages directs et de propos rapportés de seconde main, qu'il s'agisse de politique, de littérature ou de la brève liaison avec George Sand.

Dans une note érudite (pp. 133-136), Jean CANAVAGGio propose de confirmer l'attribution à Mérimée par Maurice Parturier du bref compte rendu du poème de Juan Maria Maury, Esvero y Almedora, publié dans la «Revue des deux mondes» en 1841. Trois autres écrits, sans grande importance, ont été attribués à tort à Mérimée, comme le démontre Antonia FONYI qui confirme le jugement de Parturier: «Les Gentilshommes de lettres», «Armand Marrast le grand journaliste et le grand joueur de dominos», «Écrit sur album» (pp. 137-144).

6 Figure en fin de livraison une bibliographie des «Écrits critiques sur l'œuvre et les activités de Mérimée dans les domaines de l'art et de l'archéologie, 1994-2005», établie par Jannie MAYER (pp. 151-153). 